\title{
Analysis and Discussions on the Nonuniformity Problem of SCR Denitration Equipment NOx Concentration Distribution in a 600MW Coal-fired Unit
}

\author{
Xu Ketao ${ }^{1}$, He Yongbing ${ }^{1}$, Zhang Yang ${ }^{1}$ \\ ${ }^{1}$ Huadian Electric Power Research Institute Co., Ltd., Hangzhou, China
}

\begin{abstract}
Combining with an engineering example, from the aspects of SCR inlet NOx concentration distribution, flue gas velocity uniformity, ammonia injection valve opening, ash deposit, abrasion and flue arrangement, the uniformity problem of SCR denitration equipment outlet $\mathrm{NO}_{\mathrm{X}}$ concentration distribution is analyzed and discussed in a 660MW coal-fired unit. The results show that the uneven distribution of NOx concentration is caused by the combined action of many factors. In the cause analysis and solution formulation, the influence factors need be overall consideration. By adjusting the ammonia injection valve opening, the uniformity of SCR outlet NOx concentration increases by about $30 \%$, the performance of SCR denitration equipment is obviously improved. At the same time, rationalization proposals and solution measures for the improvement of outlet concentration uniformity are given in order to ensure the safe and stable operation of denitration equipment.
\end{abstract}

\section{Introduction}

Nitrogen oxides is one of the main pollutants in flue gas emissions from coal-fired units, and excessive emissions will seriously deteriorate environmental air quality and have adverse effects to human health ${ }^{[1]}$. Therefore, controlling the emission of nitrogen oxides has become one of the main tasks in the construction of a beautiful ecological environment in China. SCR flue gas denitrification technology is currently the most widely used and mature flue gas treatment technology. With the hours of equipment operation increasing, the operation state of denitrification facilities such as the diversion device, the rectifier device, the ammonia spraying grid has changed, which caused the flue gas flow field to change, resulting in the uneven distribution of $\mathrm{NO}_{\mathrm{X}}$ concentration at the outlet of denitrification equipment. This will further lead to problems and deterioration of ammonia escape rate increasing, air preheater blockage, catalyst wear and other, which will adversely affect the safe and stable operation of the denitrification equipment and even the unit, and will also lead to the phenomenon of "upside down" of $\mathrm{NO}_{\mathrm{x}}$ at the outlet of the denitrification equipment and the chimney discharge port, there is the risk of excess nitrogen oxide emissions, which has become an important technical problem to be solved by coal-fired power generation enterprises at present ${ }^{[2]}$.

\section{RESEARCH OBJECT}

\subsection{Overview of SCR denitrification equipment}

The 680MW unit boiler is designed and manufactured by Harbin Boiler Plant Co., Ltd. The boiler is ultrasupercritical variable pressure running once-through boiler, which use low NOx main burner grading combustion technology and MACT-type low $\mathrm{NO}_{\mathrm{x}}$ grading air supply combustion system, reverse tangential burning. The flue gas denitrification equipment uses SCR denitrification process, honeycomb catalyst, liquid ammonia as reducing agent. The unit design parameters of SCR denitrification are shown in table 1.

Table 1. The design parameter of SCR de-NOx equipment

\begin{tabular}{|c|c|}
\hline Item & Design Parameter \\
\hline The flue gas parameters & \\
\hline Flue gas volume flow rate $/\left(\mathrm{m}^{3} \cdot \mathrm{h}^{-1}\right)$ & 2062799 \\
\hline flue gas temperature $/{ }^{\circ} \mathrm{C}$ & 365 \\
\hline The inlet NOX of SCR $/\left(\mathrm{mg} \cdot \mathrm{m}^{-3}\right)$ & 400 \\
\hline The dust concentration $/\left(\mathrm{mg} \cdot \mathrm{m}^{-3}\right)$ & 38.8 \\
\hline The performance parameters & \\
\hline The outlet NOX of SCR $/\left(\mathrm{mg} \cdot \mathrm{m}^{-3}\right)$ & 50 \\
\hline Ammonia escape $/\left(\mathrm{mg} \cdot \mathrm{m}^{-3}\right)$ & 2.28 \\
\hline Denitrification efficiencies $/ \%$ & 87.5 \\
\hline
\end{tabular}

\footnotetext{
*Corresponding author: xukt_2010@163.com
} 
The denitrification equipment was put into operation at the end of March 2013, with the initial loading of two layers catalyst. The ultra-low emission transformation is completed at the end of 2016, and the initial loading of two layers catalyst is replaced. The denitrification ammonia-spraying grille (AIG) adopts zoning control, that is, the inlet flue section is divided into 14 regions, seven regions of the single side reactor, two ammoniaspraying pipes are set up in a single area to control the amount of ammonia sprayed at different depths, and each pipe is connected with three ammonia-spraying branch pipes, each of which can be adjusted separately to distribute the ammonia-spraying flow.

\subsection{Inlet and outlet flue monitoring points of denitrification equipment}

The reactor inlet $\mathrm{NO}_{\mathrm{X}}$ concentration and flue gas flow rate monitoring points are located at the upper horizontal flue between economizer outlet and SCR reactor inlet. The monitoring point arrangement is shown in Fig.1. The $\mathrm{NO}_{\mathrm{X}}$ concentration and flue gas flow rate distribution were measured by grid method. The number of monitoring points in the reactor $\mathrm{A}$ to $\mathrm{B}$ direction was 1A1,1A2 ...1A9,1B1,1B1,1B2...1B9, total 18 monitoring holes; the depth of flue gas sampling points in each hole was $1,2,3,4,5 \mathrm{~m}$, and the number was $1 \mathrm{P} 1,1 \mathrm{P} 2,1 \mathrm{P} 3,1 \mathrm{P} 4,1 \mathrm{P} 5$; and 90 monitoring points for the inlet flue section ${ }^{[3]}$.

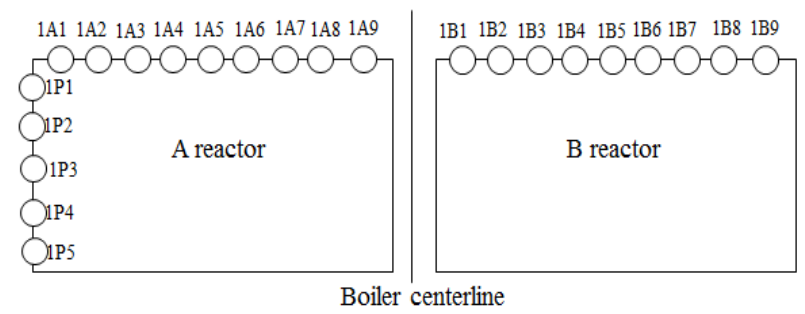

Fig.1. Monitoring points of flue inlet

The reactor outlet $\mathrm{NO}_{\mathrm{X}}$ concentration and flue gas flow rate monitoring points are located at the upper horizontal flue. The $\mathrm{NO}_{\mathrm{X}}$ concentration and flue gas flow rate distribution were measured by grid method. The number of monitoring points in the reactor $\mathrm{A}$ to $\mathrm{B}$ direction was $2 \mathrm{~A} 1,2 \mathrm{~A} 2 \ldots 2 \mathrm{~A} 12,2 \mathrm{~B} 1,2 \mathrm{~B} 1,2 \mathrm{~B} 2 \ldots .2 \mathrm{~B} 12$, total 24 monitoring holes; the depth of flue gas sampling points in each hole was $1,2,3,4 \mathrm{~m}$, and the number was $2 \mathrm{P} 1,2 \mathrm{P} 2,2 \mathrm{P} 3,2 \mathrm{P} 4$; and 96 monitoring points for the inlet flue section. The order of the monitoring points is the same as the import.

\subsection{Evaluation criteria}

The uniformity of $\mathrm{NO}_{\mathrm{X}}$ concentration and flue gas flow rate at inlet and outlet of denitrification reactor are evaluated by standard deviation coefficient (Cv.), which is defined by the following formula ${ }^{[4-5]}$ :

$$
C_{V}=\sqrt{\frac{1}{n-1} \sum_{i=1}^{n}\left(x_{i}-\bar{x}\right)^{2}} / \bar{x} \times 100 \%
$$

Where $\mathrm{X}$ is the average value of measured data; $\mathrm{X}_{\mathrm{i}}$ is the monitoring value of monitoring point.

\section{Distribution of outlet flow field of denitrification equipment}

\subsection{Distribution of $\mathrm{NO}_{x}$ concentrations}

Fig.2 shows $\mathrm{NO}_{\mathrm{X}}$ concentration distribution at outlet of denitrification reactor. From Fig.2, it can be seen that the maximum value of $\mathrm{NO}_{\mathrm{X}}$ concentration at the outlet section of A side reactor is $95 \mathrm{mg} / \mathrm{m}^{3}$, the minimum value is $10 \mathrm{mg} / \mathrm{m}^{3}$, the relative standard deviation of $\mathrm{NO}_{\mathrm{X}}$ concentration distribution is $57.58 \%$; the maximum value of $\mathrm{NO}_{\mathrm{X}}$ concentration at the outlet section of $\mathrm{B}$ side reactor is $80 \mathrm{mg} / \mathrm{m}^{3}$, the minimum value is 12 $\mathrm{mg} / \mathrm{m}^{3}$, the relative standard deviation coefficient of NOx concentration distribution is $45.07 \%$; and the mean value of relative standard deviation coefficient at the outlet of two reactors is $51.37 \%{ }^{[6]}$. It can be seen that the outlet $\mathrm{NO}_{\mathrm{X}}$ concentration distribution is highly heterogeneous, the NOx concentration distribution along the reactor width direction obviously presents the distribution characteristics of the flue lateral high and the medial low, and the middle concentration is the lowest; the depth direction presents the distribution characteristics of the upper layer concentration of the flue and the lower layer gradually decreases.
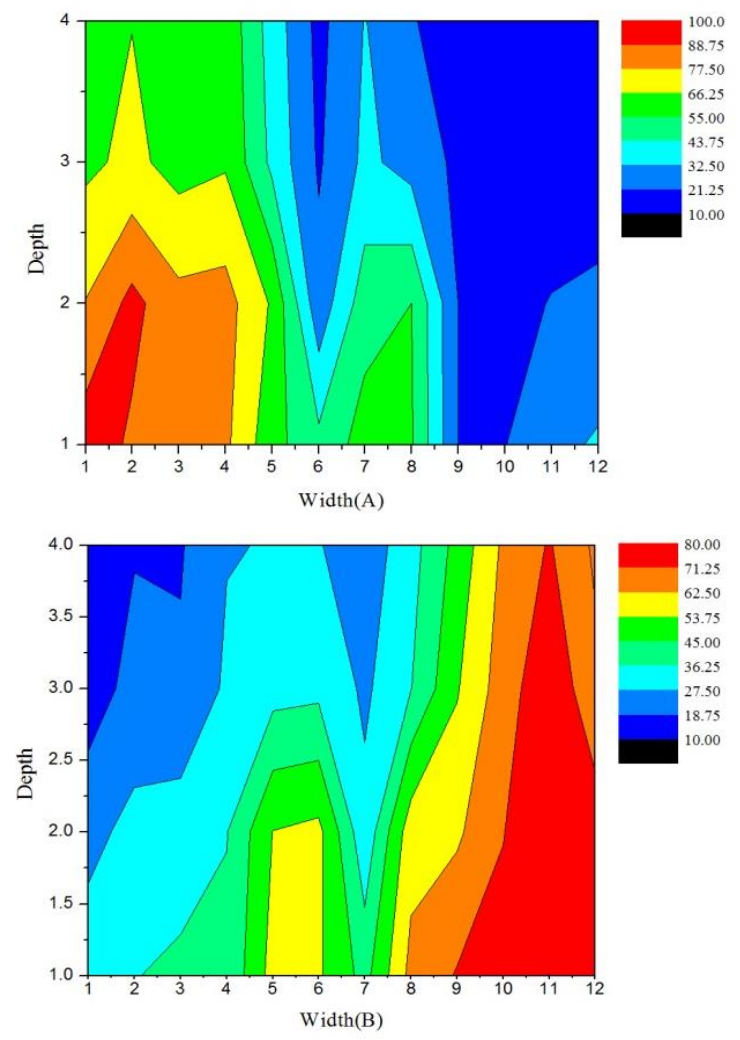

Fig.2. Distributed situation of outlet $\mathrm{NO}_{\mathrm{x}}$ concentration

\subsection{Distribution of ammonia escape rates}

The ammonia escape rate is an important operation 
parameter of SCR system, which reflects the spray amount of ammonia, the degree of mixing uniformity between $\mathrm{NO}_{\mathrm{X}}$ and ammonia, and the catalytic chemical reaction on the catalyst surface. Fig.3 shows the ammonia escape rate distribution at the outlet of the denitrification reactor. It can be seen that the maximum ammonia escape concentration in the flue section of the reactor outlet is $1.45 \mathrm{mg} / \mathrm{m}^{3}$ and the minimum value is $0.59 \mathrm{mg} / \mathrm{m}^{3}$. The ammonia escape rate of each monitoring point is within the control guaranteed value range. However, from the distribution situation, it can be seen that the outlet ammonia escape concentration unevenness is high, mainly showing the trend of high in the two sides and low in the middle of the flue, which is basically consistent with the concentration distribution of $\mathrm{NO}_{\mathrm{X}}$.

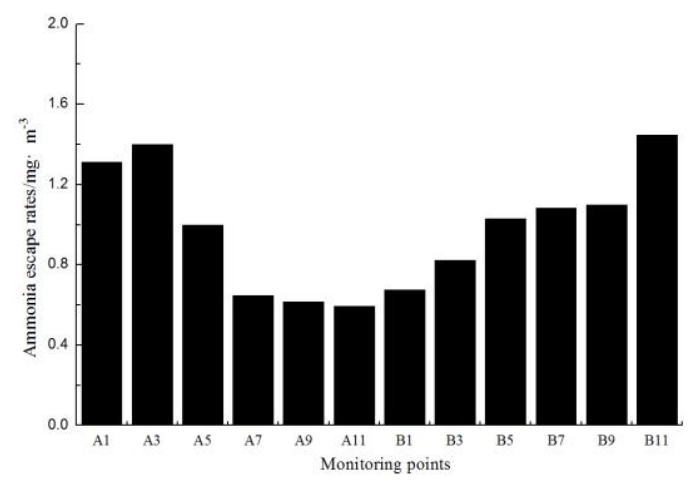

Fig.3. Distributed situation of ammonia escape

\section{Analysis and Discus distribution of outlet NOx concentration sions on the uniform}

\subsection{The distribution of $\mathrm{NO}_{\mathrm{x}}$ concentration in the inlet}

The distribution of inlet $\mathrm{NO}_{\mathrm{x}}$ concentration in the denitrification system is directly related to the spray amount of ammonia in the flue. The more uniform the $\mathrm{NO}_{\mathrm{X}}$ concentration distribution is, the more stable the denitrification efficiency and ammonia escape rate are. Fig.4 shows the $\mathrm{NO}_{\mathrm{X}}$ concentration distribution at the inlet of the denitrification reactor. From Fig.4, it can be seen that the maximum $\mathrm{NO}_{\mathrm{X}}$ concentration of inlet flue section of A reactor is $332 \mathrm{mg} / \mathrm{m}^{3}$, the minimum value is $262 \mathrm{mg} / \mathrm{m}^{3}$, the relative standard deviation of $\mathrm{NO}_{\mathrm{X}}$ concentration distribution is $6.08 \%$; the maximum $\mathrm{NO}_{\mathrm{X}}$ concentration of outlet flue section of $\mathrm{B}$ reactor is 315 $\mathrm{mg} / \mathrm{m}^{3}$, the minimum value is $261 \mathrm{mg} / \mathrm{m}^{3}$, and the relative standard deviation of $\mathrm{NO}_{\mathrm{X}}$ concentration distribution is $5.05 \%$, which is maintained near the standard deviation design value $(5 \%)$ of inlet $\mathrm{NO}_{\mathrm{X}}$ concentration. It can be seen that the $\mathrm{NO}_{\mathrm{X}}$ concentration uniformity of the inlet flue of the denitrification equipment is relatively good, and the concentration distribution of each region of the inlet flue is more uniform, only a relatively high concentration distribution appears on both sides of the flue. In the case of the same inlet flue gas flow rate, ammonia spray and so on the influence of the inlet $\mathrm{NO}_{\mathrm{X}}$ concentration distribution on the uniformity of the outlet $\mathrm{NO}_{\mathrm{X}}$ concentration distribution is relatively small.
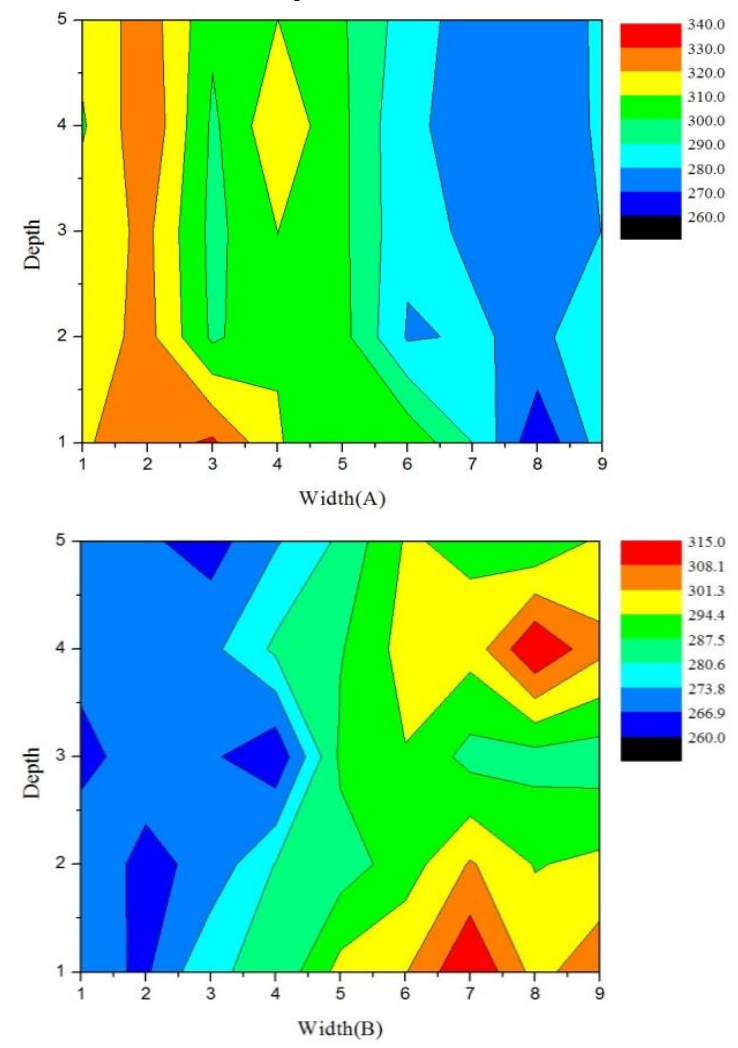

Fig.4. Distributed situation of inlet $\mathrm{NOx}$ concentration

\subsection{Distribution of inlet velocity field}

The inlet flue gas flow rate of denitrification equipment is one of the important factors affecting the mixing of flue gas and ammonia ${ }^{[7]}$. Fig. 5 shows the inlet velocity field distribution of the denitrification reactor. The grid method is used to measure the dynamic pressure of each measuring point of the inlet flue. According to the test results, the average flue gas velocity of the inlet flue of the $A$ and $B$ side reactor is $11.87 \mathrm{~m} / \mathrm{s}$ and $12.30 \mathrm{~m} / \mathrm{s}$, the relative standard deviation of the flue gas velocity distribution is $35.8 \%$ and $28.9 \%$, the difference value of maximum and minimum flow velocity is $14 \mathrm{~m} / \mathrm{s}$, and the velocity distribution deviation is large, the velocity field is relatively uneven, showing the characteristics of high on both sides and low in middle of the flue. And the relative standard deviation of the inlet flue gas flow rate of the ammonia spraying grille on both sides of A and B is higher than the design requirement of $15 \%$, which is mainly limited by the construction conditions of the site, the steering of the outlet flue of the economizer causes the air flow to deflect, or the installed diversion device is offset, that leads to the increase of the unevenness of the flue gas flow rate. In the case of uniform $\mathrm{NO}_{\mathrm{X}}$ concentration distribution at the inlet of the denitrification equipment, the flue gas flow rate is high and the flue gas flow rate is large, and the outlet concentration of the denitrification reactor is higher under the same amount of ammonia injection ${ }^{[8]}$. In 
conclusion, it is found that the inhomogeneity of inlet flue gas velocity field is one of the reasons for the uneven distribution of $\mathrm{NO}_{\mathrm{X}}$ concentration at the outlet.
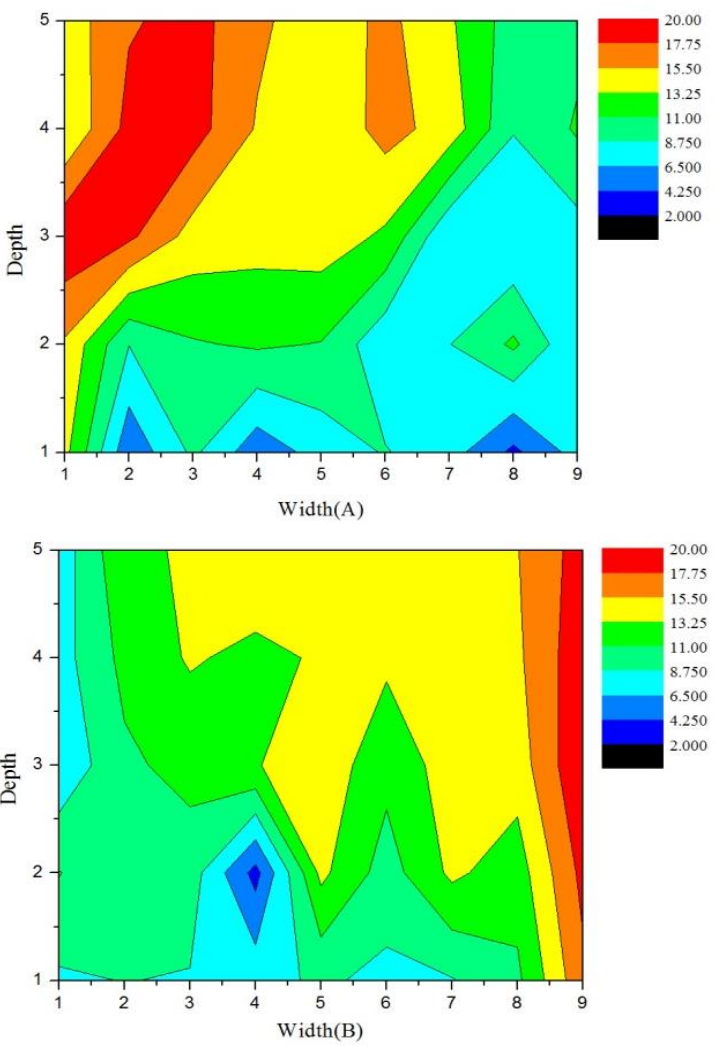

Fig.5. Distributed situation of inlet flue gas velocity

\subsection{Number of ammonia injection control valve}

Opening of ammonia injection control valve is the key factor affecting the size of ammonia spray. The opening is large, the spray amount of ammonia is large, and the $\mathrm{NO}_{\mathrm{x}}$ concentration at the outlet of the corresponding area is low. Fig. 6 shows the regulating valve opening and ammonia injection pressure of each ammonia injection branch. From Fig.6, it can be seen that the overall change trend of valve opening and ammonia injection pressure of ammonia injection regulation is basically the same, the pressure of ammonia injection at each point is above $1200 \mathrm{~Pa}$, the circulation of ammonia gas in the area is good, and the possibility of blockage of ammonia injection pipeline is low. The opening of the ammonia spraying pipe at both ends is relatively small, the amount of ammonia spraying is relatively low, and the outlet $\mathrm{NO}_{\mathrm{X}}$ concentration is higher; the opening of the middle area of the flue is relatively large, the amount of ammonia spraying is large, and the outlet $\mathrm{NO}_{\mathrm{X}}$ concentration is lower. In general, the valve opening of ammonia regulating valve has a strong correlation with the distribution of $\mathrm{NO}_{\mathrm{X}}$ concentration at the outlet.

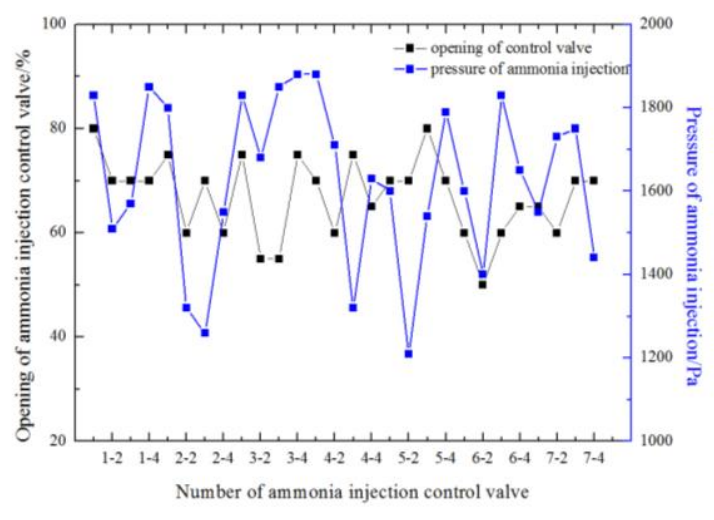

Fig.6. Opening of ammonia injection control valve

\subsection{Catalyst wear and ash deposition}

The denitration equipment adopts high dust arrangement, and the motion impact of fly ash particles in the flue will produce deposition and bypass phenomenon in the local area of the reactor ${ }^{[9]}$. When the content of alkaline metal oxides (e.g. $\mathrm{K}_{2} \mathrm{O}$ and $\mathrm{Na}_{2} \mathrm{O}$ ) in ash is high, it is easier to form ash in the nozzle, flue, flow-sharing device and catalyst layer. When the catalyst layer appears ash deposition, the chemical reaction between $\mathrm{NO}_{\mathrm{X}}$ and ammonia on the catalyst surface is prevented, and the $\mathrm{NO}_{\mathrm{x}}$ removal cannot be realized. At the same time, it causes the change of flow field in the reactor, intensifies the occurrence of catalyst wear problem, and when serious, the catalyst is worn through, resulting in a significant increase in the concentration of NOx outlet in this area. The study shows that the ratio of $\mathrm{SiO}_{2}$ and $\mathrm{Al}_{2} \mathrm{O}_{3}$ in the chemical components of fly ash is usually used as an important index to measure the wear characteristics of fly ash, the larger the ratio, the more serious the wear. When the ratio exceeds $60 \%$, the wear will be significantly aggravated ${ }^{[10]}$. According to the results of fly ash analysis (as shown in table 2), the ratio of $\mathrm{SiO}_{2}+\mathrm{Al}_{2} \mathrm{O}_{3}$ accounts is about $80 \%$ of fly ash, and the wear of fly ash is relatively strong, and there is a risk of catalyst wear problem.

Table 2. The analysis of ash components

\begin{tabular}{cc}
\hline Item & Analysis Result \\
\hline $\mathrm{SiO}_{2} / \%$ & 49.70 \\
$\mathrm{Fe}_{2} \mathrm{O}_{3} / \%$ & 6.56 \\
$\mathrm{Al}_{2} \mathrm{O}_{3} / \%$ & 28.49 \\
$\mathrm{CaO} / \%$ & 6.94 \\
$\mathrm{MgO} / \%$ & 1.07 \\
$\mathrm{TiO}_{2} / \%$ & 0.62 \\
$\mathrm{SO}_{3} / \%$ & 3.11 \\
$\mathrm{P}_{2} \mathrm{O}_{5} / \%$ & 1.10 \\
$\mathrm{Na}_{2} \mathrm{O} / \%$ & 1.57 \\
$\mathrm{~K}_{2} \mathrm{O} / \%$ & 0.84 \\
\hline
\end{tabular}

Fig. 7 shows the outlet velocity distribution of the denitrification reactor. As can be seen from Fig.7, the 
flow rate of the flue gas outside the A-side and B-side reactors is lower, especially the B-side is obvious. A single lower flue gas flow area appears in the middle part of the A-side and B-side reactors, considering the presence of beams at the front end of the monitoring area, which affects the flue gas flow. By calculation, the relative standard deviation of flue gas velocity is $25.8 \%$ and $29.5 \%$, and the overall uniformity of flue gas velocity distribution is poor. Combined with the distribution of outlet $\mathrm{NO}_{\mathrm{X}}$ concentration, considering the possibility of ash deposition and wear in the catalyst near the outer part of the reactor, it is easy to cause the local area flue gas flow to increase, and beyond the catalytic removal capacity of the catalyst to cause the increase of the emission concentration in the region. Therefore, it is suggested to check the ash and wear of the catalyst in the reactor during the maintenance period and dispose of it in time.
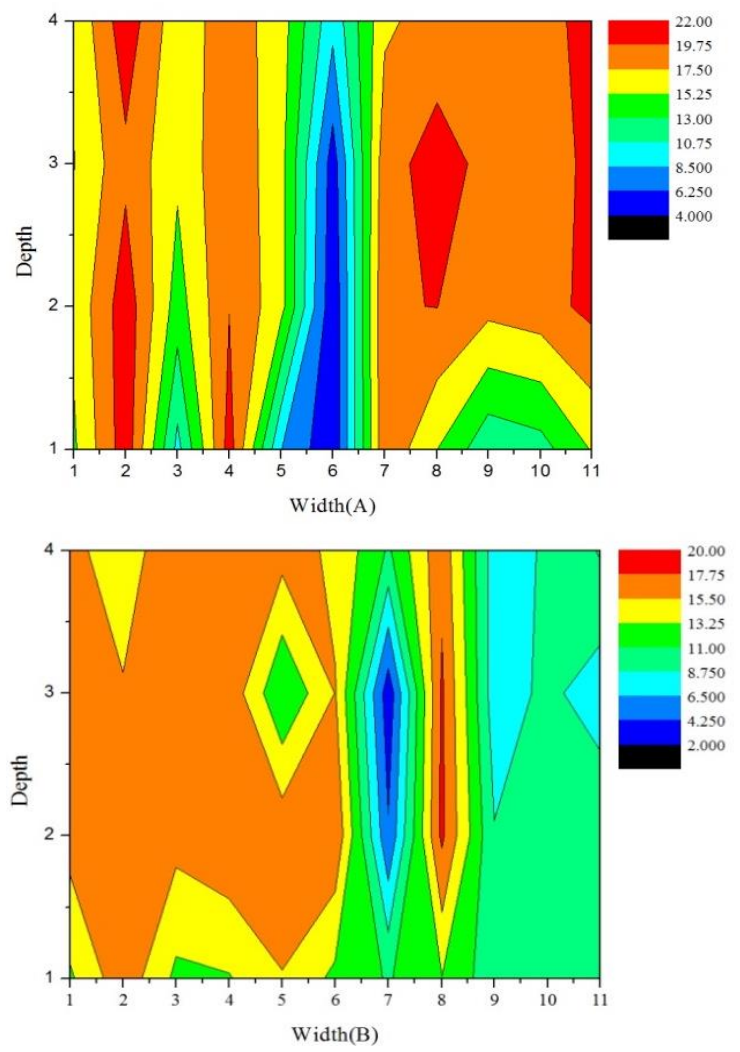

Fig.7. Distributed situation of outlet flue gas velocity

\subsection{Flue arrangement}

Figure 8 is the flue arrangement of SCR denitrification equipment. As can be seen from Fig.8, from the ammonia-spraying grid to the upper catalyst, there are 1 abrupt cross section and 3 flue elbows in the whole flue gas strike. The flow field distribution is uneven due to the abrupt change in the flow line of the flue gas through the abrupt cross section, especially near the outside of the flue (no gradual expansion section on the inside of the flue). At the same time, when the flue gas flows through the first flue elbow, the flue gas is pressed to the outside of the elbow by centrifugal force, so that the low-speed triangle zone appears on the inside, resulting in uneven distribution of the flow field. When flue gas diffuses from horizontal into reactor, it will flow along the flue wall, that is easy to form a high-speed scour zone on the outside of the reactor and a reflux zone on the inside, which seriously affects the flow field uniformity and the residence time of the flue gas in the catalyst layer, and then leads to the decrease of denitrification efficiency and the increase of ammonia escape rate, which is one of the reasons why the upper concentration of the outlet flue is higher than that of the lower part.

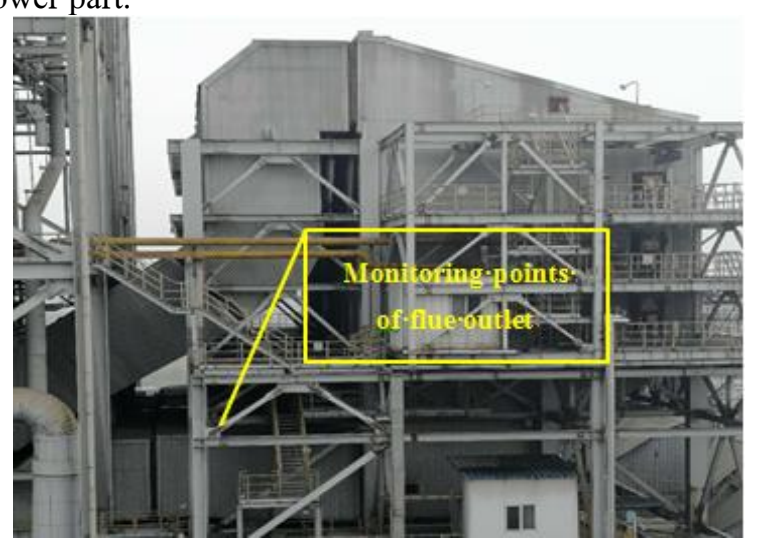

Fig.8. The plan of flue arrangement

\subsection{Operation after ammonia injection adjustment}

In view of the uneven distribution of $\mathrm{NO}_{\mathrm{x}}$ concentration at the outlet of the SCR denitrification equipment of the unit, the adjustment test of the opening of the valve for regulating ammonia injection in the field was carried out [11]. Figure 9 shows the effect of the adjusted outlet $\mathrm{NO}_{\mathrm{X}}$ concentration distribution. As can be seen from figure 9, the maximum concentration of $\mathrm{NO}_{\mathrm{X}}$ in the outlet flue of the A-side reactor is $33 \mathrm{mg} / \mathrm{m}^{3}$ and the minimum is 15 $\mathrm{mg} / \mathrm{m}^{3}$; the maximum concentration of $\mathrm{NO}_{X}$ in the outlet flue of the B-side reactor is $34 \mathrm{mg} / \mathrm{m}^{3}$ and the minimum value is $15 \mathrm{mg} / \mathrm{m}^{3}$; the relative standard deviation of the A-side and B-side reactors is $23.06 \%$ and $22.01 \%$, which optimizes the operation of the denitrification equipment to some extent, alleviates the inhomogeneity of the outlet NOx concentration, effectively improves the denitrification efficiency and reduces the ammonia consumption. However, only adjusting the valve opening of ammonia injection cannot meet the uniformity requirements of the design, the uneven coefficient of outlet concentration distribution is still large, and there is still a high concentration area in the local area. In order to further improve the uniformity of the outlet $\mathrm{NO}_{\mathrm{X}}$ concentration, it is suggested that the next step should be to make use of the downtime inspection period to comprehensively check the possible problems from the aspects of ammonia spraying grille (nozzle), ash deposition in the flue, the change of the arrangement of the flow-sharing device, the ash deposition and wear of the catalyst, and formulate the corresponding solutions. 

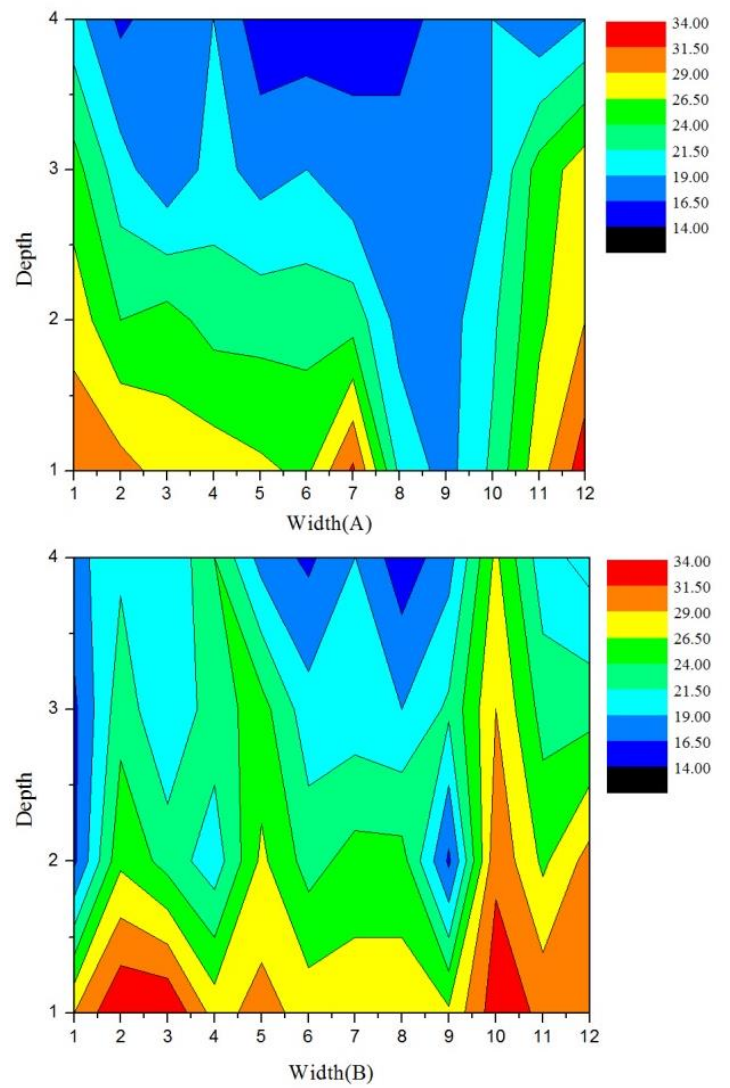

Fig.9. Distributed situation of outlet $\mathrm{NOx}$ concentration after ammonia injection adjustment

\section{Conclusion}

The results show that the uneven distribution of $\mathrm{NO}_{\mathrm{X}}$ concentration at the outlet of SCR denitrification plant is caused by the joint action of imported $\mathrm{NO}_{\mathrm{X}}$ concentration, flue gas flow rate, ammonia spray regulating valve opening, ash deposition and wear, and flue arrangement, etc. The specific gravity of each factor should be taken into account in the cause analysis to find the most appropriate solution. By adjusting the opening of the valve with ammonia injection in different regions, the uniformity of the $\mathrm{NO}_{\mathrm{X}}$ concentration field at the SCR outlet was significantly improved, and the uniformity was improved by about $30 \%$. To further improve the uniformity of the outlet concentration, we can consider starting from the establishment of numerical simulation and cold state physical model test of denitrification equipment, re-accounting for the SCR flow field distribution, reasonably adjusting the number and layout of the diversion and rectifier units, and replacing the severely worn catalyst, and so on. In addition, in order to improve the accuracy of the on-line monitoring data and avoid the problem of inconsistency between the $\mathrm{NO}_{\mathrm{X}}$ concentration at the denitrification outlet and the total outlet, we can consider changing the existing single point on-line monitoring mode to multi-point or matrix sampling mode to expand the online monitoring range.

\section{References}

1. Meng Yongjie, Li Weizhi, Zhang Tao, et al. Operation status analysis of an SCR system for 350MW supercritical units[J]. Power Equipment, 2018, 32(4):253-256.

2. YE Xinglian, YANG Ding, GUO Jun, et al. Flow field optimization of SCR De-NOx project for ultralow emission retrofit[J]. Chinese Journal of Environmental Engineering, 2018,12(6):1725-1732.

3. MA Dawei, ZHANG Qiliang, HUANG Qishun, et al. Assessment of $\mathrm{NO}_{\mathrm{X}}$ distribution and ammonia escape on centration at SCR outlet after ultra-low emission retrofit[J].Electric power,2017,50(5):168171.

4. MAO Yisheng, WU Zhipeng, ZHANG Xiaotian. Optimization and adjustment of ammonia injection system and improvement of flue gas sampling method for SCR denitrification system of thermal power plants[J].Electric power,2017,50(4):167-171.

5. LI Tong. Ultra-low emission reconstruct of denitrification system based on $\mathrm{NO}_{\mathrm{X}}$ uniformity test of SCR reactor[J]. Chinese Journal of Environmental Engineering, 2018, 12(4):1112-1119.

6. ZHOU Xingang, LIN Xiao, ZHAO Qingchuan, et al. Optimal experiment of selective catalytic reduction in $300 \mathrm{MW}$ coal-fired Units[J]. Power System Engineering,2016,32(2):43-46.

7. Li Hantian. Influence of non-uniform distributions of inlet velocity and reluctant on SCR De-NOX performance [D].Beijing: Tsinghua University, 2016.

8. LUO Zhi, XU Jian, LI Bin, et al. Optimization of flow field in SCR denitration system for boiler burning highly contaminated coal[J].Thermal Power Generation,2018,47(12):111-117.

9. GAO Jianqiang, LIANG Shengying. Optimization and experimental research on SCR denitration system [J].Electric Power Science and Engineering, 2018,34(10):56-62.

10. SUN Yezhu, WANG Yibing, LIANG Xuedong, et al. Discussion on installation of ash hopper and enlargement of flue section before SCR for coalfired power plant $[\mathrm{J}]$. Electric Power Construction, 2011, 32(12): 64-68.

11. CHEN Cheng. The necessity and method of optimized adjustment for the spraying ammonia grille of SCR denitration system [J].Industrial Safety and Environmental Protection,2018,44(9):11-12,24. 